\section{Post-docs take up ARMS}

\section{Short term research contracts are leading scientists to rebel, writes Joe Schwartz}

THE organisation of scientific research in the UK has evolved to the point where there are now 10,000 people employed to do research on short term contracts and an additional $1,800 \mathrm{PhDs}$ registered as unemployed with the Department of Employment. Combine these figures with recent cuts in public spending and the result is the inevitable development of labourmanagement conflict in an area of the economy that has always considered itself immune from such pressures. And, wherever a management view in defence of short term contracts is articulated (contracts are for specific pieces of work, the scientific mind burns out early in life, unfruitful research lines can be easily terminated), there is a labour point of view articulated by short term contract workers themselves.

ARMS, the Association of Researchers in Medical Science, is one organisation that is attempting to speak for the needs of full time researchers employed in the nation's hospitals and medical schools on short term contracts.

Based at Guys Hospital in London. ARMS was formed after a series of public meetings in July 1978 . Its principal goal is to establish a career structure for full time non-teaching researchers analogous to university lectureship scales. Although not ruling out trade union affiliation, the organisation at present intends to negotiate with employers and to do educational work in an effort to change the present arrangements.

Membership in the organisation received a boost in September when the University of London which administers Guys instituted waiver clauses in short term contracts. Seeking to prevent 'onerous benefactions' to the research staff. the university demanded that researchers relinquish their rights to redundancy pay and claims against unfair dismissal. The outcry against this particular action has cast the university into the role of a 'bad' employer and could be rescinded if the researchers are able to maintain an active resistance to the measure. Brian Davis, Labour MP for Enfield and a member of the MRC, acknowledges that the MRC would like 'maximum flexibility' in its hiring and firing but is working to abolish the waiver clause as soon as possible. The Cancer Research Campaign, located at Mt Vernon Hospital, has removed the

Dr Joseph Schwartz is on leave from City University, New Yorl: waiver clause after protests from the researchers there.

The waiver clause, however, is only the most recent grievance. Dr Mick Kadlubowski, Information Officer of ARMS, regards administrators' arguments in favour of contract work as specious and self serving. "The system prevents the untenured full-time researcher from having an effective say in research policy. Should a project be successful the honours accrue to the grant holder; if not, then support for the unfruitful line can be terminated and the untenured scientist is once again looking for a job". This practice particularly affects women scientists. It is common for younger women scientists to be given the riskiest research lines since senior researchers tend to take their scientific ambitions less seriously than those of their male colleagues because women bear children.

As for the question of 'burn outs'. Kadlubowski points out that such a fate does not seem to affect administrators and clinicians. "Project grant applications are on the whole successful only when submitted by those with tenure and are usually assessed by their tenured colleagues. The ability of these senior academics and clinicians to devise and judge a research proposal would not appear to wane".

According to ARMS' analysis the present system is costly and wasteful.

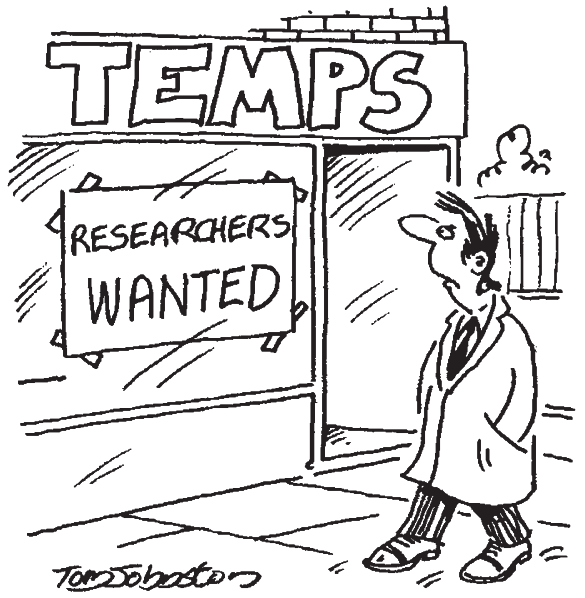

One half of a researcher's time on a short term contract is spent settling into the project and then towards the end looking for a new job. After two or three contracts, the researcher is 30-35 years old and the contractors begin to find the price of experience too great. The experienced researcher is told to seek employment elsewhere and the funds thus 'saved' are used to boost the intake of juniors. "How can science progress when hard-won experi-

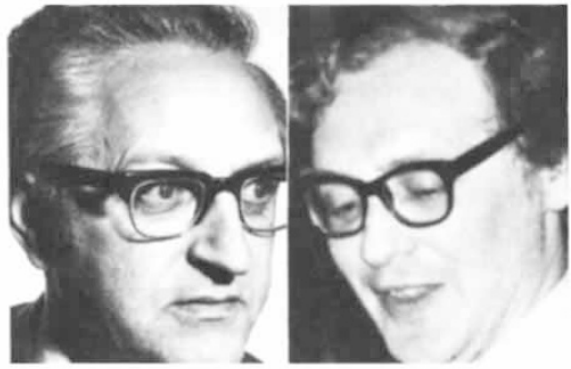

Davison of ASTMS; Akker of AUT.

ence is so callously thrown away", asks Kadlubowski.

ARMS has approached the DES and the MRC with little effect. Dr Anne Simmonds, chairperson of ARMS, is scathing about a recent MRC grant scheme : five-year renewable grants to age 35 , grants to permit tenured academics to do full time research for a short time, and external full time research professorships for the clinically qualified. "At this critical time with their scant funds and these alarming unemployment statistics," she says "the MRC comes up with funds to allow the tenured time off to dabble in full time research, the clinician the opportunity to return to the field and progress without restraint to the professorial level, and another ten years of insecurity offered to the non-medically qualified."

The action of the MRC in totally ignoring the most urgent problems, the scandalous plight of full-time nonmedically qualified researchers despite representations from clinical professors, deans of medical schools and the scientists themselves is utterly reprehensible".

Anne Simmonds is equally critical of university administrators. "Instead of raising their voices in support of some urgent action to resolve the situation they are aggravating it by looking for loopholes in the law to enable them to escape any commitment to their fulltime researchers whatsoever."

Faced with this response from employers ARMS members have contacted ASTMS and the AUT, the two trade unions involved. "ASTMS calls us elitist and they want money on the line before they'll do anything", say members of the executive committee. Stan Davison, assistant general secretary of the 460,000-member ASTMS, denies this charge but admits that the problems of organising short term contract workers are formidable; the workforce is spread out over the entire country in small pockets of twos and threes; many scientific workers are indifferent or even hostile to trade unions; and research workers tend to be inexperienced and sympathetic to management arguments.

ASTMS is opposed to short term contracts and the unregulated em- 
ployer-employee relationship that currently prevails. Philip Hounsell, division organiser for ASTMS at Guys Hospital welcomes an organisation like ARMS. Hounsell feels that only by rank and file organising at the local level can sufficient strength be built to have a real effect. Both Davison and Hounsell emphasise however that without proper trade union organisation and support it is doubtful whether the authorities can be persuaded to act.

The 30,000 member AUT is approaching the problem at a higher level. It has negotiating rights for the universities and successfully negotiated national salary scales for researchers in 1975. John Akker, deputy general secretary, says that the AUT handles "scores of cases" of senior research workers, many with international reputations who have been made redundant at the age $40-45$. The hardship is even worse he says because "many people are so specialised as to be unemployable".

The AUT offers legal services to members faced with dismissal and has been able to negotiate cash settlements in many cases and is in the process of formulating a code of practice for the employment of research staff. The AUT is attempting to move its efforts into the ministerial arena. "The MRC claims that the universities are the

\section{People before pounds, say SRC}

Britaln's Science Research Council is no longer so worried about money, but is finding itself with another problem: manpower. The chairman of the SRC, Professor Geoffrey Allen, said last week that "the manpower problem is preventing us from diversifying".

Professor Allen was presenting a fairly encouraging annual report for the year to April 1978. The budget reduction of $1.7 \%$ per year imposed on the SRC by the Advisory Board for the Research Councils had been held to $1 \%$, and merely another $£ 20$ million over the next $4-5$ years would make the SRC comfortable. A 2-3\% increase in the 'science vote' (the money allocated to the ABRC by the government for disbursement to the research councils) would give the $A B R C$ all that the ABRC thinks is needed nationally.

Professor Allen is taking the training function of the SRC very seriously, and hopes to introduce courses for "topping up" in new technologies. This is "the major issue now" in training. And he wants to introduce a five person "think tank" into the Council which will concern itself with improving the links between university and industry. This call for five new people employer and the universities say since the MRC provides the money it is up to the MRC to sort it out", says Akker. Even if the research councils were to become actively involved there are still 78 autonomous institutions to deal with. The AUT wants the government to convene a committee with trade unions, universities, research councils and government representatives on it.

Whether the government is prepared to take on the issure is unclear. Certainly the universities are acting as if they have just discovered 19th century labour relations. Insisting on the value of piece work places academia in the league of garment manufacturers in a pre-trade union situation. This sensibility is reproduced in many researchers themselves who accept the line that a good student can always find a position and who reject trade union protection as being unprofessional.

But since research is an integral part of a modern economy some pressure exists for researchers to be able to make some changes. Certainly young potential scientists will begin to reject a scientific career if they become aware of the true conditions of research work. And there is nothing to prevent out of work scientists from organising just such a campaign if they are angry enough.

underlines Professor Allen's concern for SRC manpower.

The development of new activities at the Rutherford and Daresbury laboratories, whose subnuclear physics accelerators were closed in the year under review, is also raising manpower problems. The SRC, like many other government bodies, is under a directive to reduce its manpower -in the SRC's case at $1 \%$ per annum. This would mean a loss of some 30 people per year; but with fairly young staff it is a hard target to reach through natural wastage and early retirement.

While it has been possible to retrain many of the displaced high energy physicists at Rutherford and Daresbury in subjects like energy research and computing, it is not so easy to turn a physicist into a biologist to run, say, a biology support team at the new synchrotron radiation source. The central problem is that a few key people are needed, with special talents, to implement the changes which Professor Allen would like the SRC to undergo. "We now need different types of scientists to maintain our central facilities and links with universities", says Professor Allen. The SRC is a potential employer of scientists. But at the moment it is being held back.

Robert Walgate

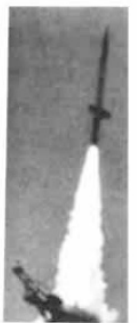

Skylark rockets could be made from spare parts say UK geophysicists

A GROUP of UK geophysicists has come up with an idea which, in the early 1980 s, could help soften the blow on auroral physics of the Science Research Council's (SRC) cutback in 'big science'. It has suggested that component parts left over from the SRC's abandoned Skylark rocket programme could be used to build as many as twelve extra Skylark rockets.

The decision to abandon the Skylark rocket programme was taken in 1975-6 as part of the SRC's plan to economise on 'big science'. Since then the British Aircraft Corporation, the rockets' manufacturer, has been slowly winding down production. Only one rocket now remains to be launched from Woomera, Australia, next May. During the 21 years of the programme, more than 250 Skylark rockets have been successfully launched.

The UK rocket programme now depends on two small rockets, the 7.5 inch-diameter Petrel rocket capable of launching $14 \mathrm{~kg}$ to a height of $200 \mathrm{~km}$ and the 10 inch diameter Fulmar rocket capable of launching $50 \mathrm{~kg}$ to more than $250 \mathrm{~km}$. These are used for studying the lower and mid-ionosphere.

The 17 inch-diameter Skylark rocket is capable of carrying about $150 \mathrm{~kg}$ to altitudes as high as $750 \mathrm{~km}$. It is the only UK sounding rocket developed so far which is capable of investigating the structure of the upper ionosphere and the origin of auroral particles. Although a Fulmar might have the ability to fly high enough, it does not have the capacity to carry the instrumentation needed to measure energetic incoming particles and electric fields.

The geophysicists claim that twelve Skylarks of varying size could be assembled, furnished with payloads and launched at no extra cost to the SRC's planned rocket programme over the next ten years if they were launched in fours at three-year intervals. This would mean launching fewer Petrels and Fulmars; but the value of the Skylark is such that it is thought there will be little opposition. Just how much support the idea could gain is what the group of geophysicists is trying to find out at the moment. By late next Spring it hopes to have sufficient knowledge of the interest and the kinds of experiments which could be flown to put forward a concrete proposal to the SRC for funding. 